Revista Iberoamericana. Vol. LXV, Núm. 186, Enero-Marzo 1999; 89-102

\title{
COSAS, NOMBRES, Y LA DIMENSIÓN ESPIRITUAL EN LA POESÍA DE ELISEO DIEGO: TRES APROXIMACIONES
}

\author{
POR \\ Gareth Price \\ University of Connecticut
}

INTRODUCCIÓN

A primera vista, la poesía de Eliseo Diego nos advierte de su carácter singular. Esparcida, escueta, pero llena de resonancia, tiene la sencillez ilusoria de un jardín japonés. Es una poesía distinta, aún más al compararla con la poesía hispanoamericana de su época. Con su empeño obstinado de mostrarnos la profundidad de las cosas humildes, comunica un afecto secular, pero sin embargo religioso, hacia el mundo. El mundo, mirado, recordado, subrayado, se vuelve sublime, sagrado; cada parte y partícula manifiesta su significación y la inminencia de Dios. Esta poesía aparentemente sencilla logra una gran resonancia, realizando la aspiración de Diego de crear una poesía de semillas que necesitan solamente de la imaginación fértil del lector para florecer.

De los poemas de su libro Versiones, Diego ha dicho, "En ellos he tratado de dar pie al mayor número posible de significados. Por eso me producen la impresión que son físicamente mucho más extensos del tamaño que realmente tienen" (Poetas Comunicantes $150)$. Sus poemas así aparecen como una caja mágica cuyo interior es más grande que su exterior. Con gran economía de lenguaje, pinta cuadros esenciales, el punto de partida para imágenes más profundas.

Diego afirma que su primer impulso fue escribir novelas, como Dickens, pero descubrió dentro de Great Expectations una escena que parecía contener el libro entero. Diego resolvió olvidar las novelas y escribir solamente estas escenas, cada una la médula de una novela. Comenzó con cuentos cortos, luego poemas largos, y restringiéndose "a una economía cada vez mayor del idioma [...] se atreve por fin a jugar con el silencio" (149).

Pero, ¡qué silencio! Cuanto menos habla, dice más. El silencio de Diego se llena con el susurro de múltiples sentidos, sin comprometerse demasiado con ninguno. Sus poemas comunican más de lo que dicen, contienen más que su tamaño y en su misterio refieren de forma ambigua y seductora a una dimensión espiritual que siempre se mantiene escondida.

Sus poemas, cortos, trazados minuciosamente con su pincel de ebanista, detallan la resistencia y flujo de la materia, objetos aferrados a la existencia contra un mar de olvido y cambio. Dice Diego, "para mí la realidad no es algo muy preciso, de contornos muy fijos, sino que siempre se está como evaporando, y para mí es parte de la función de la poesía, el resistir ese proceso de evaporación de la realidad, tratando de fijarla en un contorno nítido" 
(148). Para preservarse contra el tiempo y su transformación incesante, el poeta fija y subraya las cosas del mundo dándoles nombres. Uno de sus poemas se llama precisamente "Voy a nombrar las cosas."

Voy a nombrar las cosas, los sonoros altos que ven el festejar del viento, los portales profundos, las mamparas cerradas a la sombra y al silencio.

(En la calzada de Jesús del Monte)

NOMBRAR LAS COSAS

En las manos de Diego, el acto de nombrar se vuelve mágico, jamás el acto simple que podría parecer. Consciente del poder creador del poeta, desteje a la vez que define, evoca la inestabilidad del sistema lingüístico y la imposibilidad de saber, roza el misterio antiguo y moderno de la ontología. Siempre da nombre a objetos humildes de su ámbito cotidiano, las cosas simples que se encuentra en casa y calle. Construyendo todo un universo físico a la vez que espiritual, invoca los muros, la madera, cornisas, vidrios, hierros y las campanas de su calle.

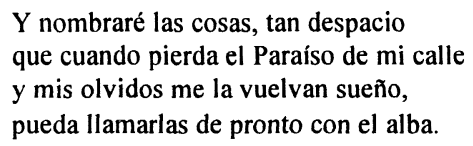

El objeto lingüístico construido, procede a girar a su alrededor, dibujándolo sucintamente de perspectivas distintas. Diego dice que él lucha para "hacer pasar la realidad al 'medio' de la palabra, sin quitarle ni añadirle nada; hacerla encarnar en la palabra tal como es ella, en toda su evanescencia original" (Poetas Comunicantes 152).

Resaltan en esta cita tres términos: la realidad, la palabra, y su evanescencia. Se construye una cadena de la realidad del poeta a su palabra y por ella al lector, preservando en todo momento el carácter evanescente de la realidad. Aunque aquí lo hace parecer fácil, no es siempre así; en otro lugar habla de la dificultad de este proceso, de la complejidad de nombrar. Entre el primer término y el segundo nunca hay acuerdo perfecto; las palabras tienen vida propia y pueden armar una lucha contra el poeta.

Cuando pasa de la cosa a la palabra, pugna con todos los demás sentidos "que se les han ido pegando, se les han ido adhiriendo [...] esas adherencias desvirtúan la comunicación, la destruyen, anulan el poema" (163). Entrado en el ámbito de las significaciones anteriores, la nueva iteración consigue su ser en interacción con ellas. "Como un cuadro tiene su marco, la palabra también tiene su limitación, que es el significado. Contra el significado y con el significado, hay una gran riqueza de posibilidades" (164). Un significado prosaico sirve de marco para la evanescencia, como de la misma lucha entre la iteración y sus antecedentes sale el juego posibilidades, el juego de los con y contra. La relación palabra-significado, o nombre-cosa, se complica, en el caso de Diego, intencionalmente; este enredo es fuente 
del sentido más hondo y provocativo de su poesía, la dimensión espiritual, ambivalente, a la vez antigua y moderna.

Trataremos aquí de tres vías de aproximación a Diego y a su juego de relaciones entre nombre y cosa. Cada una establece una relación distinta entre signo y significado; entre estas tres concepciones de dicha relación, Diego juega constantemente en sus poemas. Las tres fuentes o perspectivas - la filosofía norteamericana del siglo XIX, o el Transcendentalismo, ejemplificado por R.W. Emerson; la tradición iconográfica de la Iglesia Ortodoxa; y las discusiones al torno de la Posmodernidad, representada por Michel Foucault-se pueden considerar como tres posibles explicaciones de su juego de nombrar, facetas contradictorias y simultáneas.

\section{TRANSCENDENTALISMO NORTEAMERICANO}

En su rechazo patriótico de la sociedad capitalista, Diego no desecha la filosofía norteamericana. Cuando joven enseñó literatura norteamericana en Cuba; lo influye en su atención a la realidad física cotidiana, la busca de lo profundo en lo humilde. En Diego la influencia de los transcendentalistas - Thoreau, Whitman, y especialmente Emerson-se puede afirmar sin dificultad. La tradición norteamericana del Deísmo, es decir la creencia en la inminencia de Dios en el mundo, entra en su poesía con la consideración de que las cosas mundanas puedan tener alto significado espiritual.

Según Emerson, "1. Words are signs of natural facts. 2. Particular natural facts are symbols of particular spiritual facts. 3. Nature is the symbol of spirit" ("Nature" 911). Así, al acercarnos a la naturaleza nos acercamos a Dios. Usar un lenguaje más vinculado a la realidad tangible implica hablar con pureza espiritual. Uno de los primeros deístas norteamericanos, Thomas Paine, llegó tan lejos que describió el mundo físico como la verdadera palabra de Dios. "The creation is the Bible of the Deist. He there reads, in the handwriting of the creator himself, the certainty of his existence and the immutability of his power, and all other Bibles and Testaments are to him forgeries" (Age of Reason 184).

En Diego también vemos semejante encomio del mundo físico. Al buscar las cosas simples, busca siempre su significado transcendental, que reside dentro de la materia, pero representa e implica más, en una dimensión espiritual. Dice Diego, "lo que he tratado de hacer es recrear un lugar 'presente' que sea un poco ése de que se habla en la misa: 'el lugar del consuelo, de la luz, y de la paz"' (Poetas Comunicantes 152). Eso se puede comparar bien con los transportes que experimentaban Emerson y Whitman, y con los propósitos de su poesía. Según el Deísmo tanto como su variante, el transcendentalismo, el mundo es la representación de hechos espirituales. Cuando empleamos las palabras para representar el mundo, y lo hacemos fielmente, también manifestamos a Dios. Esta ecuación se compone así de tres términos, con los cuales se puede formar un triángulo: la palabra (del hombre), el hecho natural (palabra de Dios) y el hecho espiritual.

Por la cercanía entre los primeros dos términos llegamos al tercero. El impulso renovador de la lengua es hacia un lenguaje menos abstracto; para hablar con más verdad espiritual, usamos palabras más arraigadas en la naturaleza. Alguna vez la brecha entre palabra y significado, y entre hombre y Dios, fue menor; intentamos, nombrando las cosas 
de nuevo, fielmente, cerrarla otra vez. Diego destaca este proceso de acercamiento del mundo natural y la dimensión espiritual en el poema "Viene":

\section{VIENE}

Viene entre la lluvia, mojándose alegremente, con una vara en la mano.

Viene entre los árboles, pasando junto a los bancos desiertos a través de la lluvia, como si nada.

Viene y ya se ha ido - tú ves- y no hay más que la lluvia en los cristales.

Viene y ya se ha ido como si nada.

(Versiones)

Qué (o quién) es lo que viene (y ya se ha ido) no se dice; es una presencia efímera, que puede ser cualquier persona - quizás un muchacho jugando en la lluvia-o puede que no sea nadie sino la esperanza misma; lo que viene no se limita por definirse; deja en lugar de un contorno fijo un misterio. Sin embargo nos viene, entre la lluvia y los árboles, mojándose alegremente, fuertemente vinculado a e interpenetrado con lo natural, por lo cual no deja de ser sobrenatural. Esta interpenetración de la naturaleza y el personaje misterioso la observamos desde dentro de una casa, separados tanto del visitante como de la lluvia por los cristales. No experimentamos la misma unión mística con la lluvia a causa de nuestra lejanía como espectadores o lectores, pero podemos imaginarla; de hecho, el no definir el visitante misterioso deja un hueco abierto en la lluvia, que el lector/espectador puede sentir más plenamente. Diego experimenta con varios niveles de significados: los cristales también pueden representar las mismas palabras del poema, por las cuales miramos el hecho narrado(la unión del misterio con la naturaleza). Al fin, sólo la lluvia queda, persistentemente, al otro lado de los cristales.

En otro libro, Muestrario Del Mundo o Libro de las maravillas de Boloña, Diego comienza a reemplazar las palabras con dibujos. También hay un antecedente norteamericano para este experimento (si bien es improbable que Diego estuviese familiarizado con la tradición, pertenece a la misma corriente del Deísmo). John Irwin, en American Hieroglyphics, señala una tradición de Biblias jeroglíficas, compuestas algunas de forma de rebus, es decir, ilustraciones tomando el lugar de las palabras o sonidos dentro del texto y otras también en forma puramente ilustrativa, donde las ilustraciones forman el foco del texto, por ejemplo dibujos de santos encima de los salmos. Dice Irwin, "Riker's $A$ New Hieroglyphic Bible, by using pictures to represent objects or ideas and never to stand simply for discrete sounds, follows an ideographic tradition [...] of an original language of physical objects that preceded a language of spoken words" (31). Aunque no conociera Diego estos textos, podríamos afirmar que su iniciativa y la estudiada por Irwin coinciden en sus motivos trascendentales. 


\section{ICONOGRAFIA ORTODOXA}

Cuando emplea ilustraciones en su poesía, Diego se acerca también al icono religioso, cuya tradición cita como influencia en su poesía. Dice Diego:

Los ortodoxos piensan que los iconos son fragmentos del universo resurrecto. Cada icono es, para los ortodoxos, un pedacito del universo, tal como será, después de la resurrección en que ellos y yo creemos. Cada cuadro, cada poema, es en cierto modo algo similar (Poetas Comunicantes 150).

Los iconos tienen una existencia problemática, histórica y teóricamente. Una imagen sagrada se compone de ambos materia y espíritu. En los principios de la Cristiandad, se prohibían imágenes sagradas de Dios mismo por ser blasfemas (así como se prohibe cualquier representación en el arte islámico). Luego de la prohibición inicial, las imágenes de Cristo y los santos llegaron a tener popularidad, siendo menos problemáticas porque Cristo y los santos han tenido existencia mundana, mientras que Dios, según los viejos cristianos, no se incorpora.

Los iconos funcionan de una manera curiosa - capacitan un conocimiento de la divinidad:

"Since we are fashioned of both soul and body", our saint [John of Damascus] says, "and our souls are not naked spirits, but covered, as it were, with a fleshly veil, it is impossible for us to think without using physical images" (Barasch 216).

Este velo de la materia no cubre el espíritu completamente; no nos deja en oscuridad total. Dice Epiphanius:

The name "Christ" implies two natures, the one being visible and the other invisible. Thus this Christ, while visible to men by means of the curtain, that is his flesh, made the divine nature - even though this remained concealed — manifest through signs (Sahas 156).

Esta cortina carnal es, en el caso de la imagen el cuerpo del santo, la que cubre y revela su espíritu; en el caso de la poesía es la "realidad" a que se refieren las palabras, el significado mundano; en ambos casos sirven de puente entre el lector/espectador y el significado espiritual.

The sacred icon mitigates the full force of the divine, a force we would not be able to endure. But at the icon of God we can look. On the other hand, the bodily forms shown in the icon are transparent towards the holy; they enable us to get a glimpse of the sacred or divine (Sahas 216).

Sin embargo, esta relación se complica: desde el punto de vista de los místicos cristianos y otros, toda realidad no es mas que un velo separándonos del más allá. Esta creencia llegó a afectar la tradición de representación icónica. En las estaciones de los iconos, el velo (el mundo o el cuerpo divino) que nos separa del más allá se comienza a 
representar a nivel secundario por una cortina de madera agujereada que divide los iconos del resto de la iglesia. Ya no se puede ver los iconos directamente, sino a través de esta barrera nueva, cuya función es recordarnos la imposibilidad de ver lo divino directamente: "The metaphor of the flesh of Christ as the "curtain of the temple' is obvious: Christ in flesh is the means through which man encounters existentially, and gains a glimpse of the divine" (Barasch 156).

Debido a su historia problemática - la blasfemia de representar precisamente a los santos o a Cristo de forma que pudiéramos imaginar que los dibujos sean substitutos y no representaciones - la tradición pictórica de los iconos se quedó muy estilizada. Representan una salida determinada del realismo; mientras en otros campos de la pintura coetánea se buscaba representar cada vez con más verosimilitud sus objetos, los iconos seguían con caras planas y gestos rituales. No se permite, con su manierismo y con la cortina de madera, confundir su representación con la realidad; siempre nos advierten de su artificio, su carácter de representación. De esta manera, al contemplar los iconos se contempla también lo que no se puede ver, sea el icono mismo, el cuerpo de Cristo, o tras él, Dios mismo. La ecuación tiene así dos pasos de la representación al plano espiritual.

Mientras los Transcendentalistas buscaban llegar a la dimensión espiritual por la concordancia de la palabra y la naturaleza, la iconografía problematiza esta relación, para que no olvidemos que el icono es una representación, y no la cosa en sí; subrayar su artificio intenta volver la atención del religioso hacia el misterio ausente.

La poesía de Diego invita a muchas comparaciones con la iconografía. Mientras las figuras se sirven de la estilización para destacar su separación del referente espiritual, las acciones que representan tienden al ritual. El arreglo de personas y cosas sigue una forma precisa: las personas de menor importancia sagrada aparecen más pequeñas, y más abajo de los santos; los santos se pintan junto a sus atributos, como flores o animales con que se identifican. Los gestos de sus manos son limitados y rituales. No buscan una representación naturalista sino estilizada, y no representan una acción interrumpida sino congelada, a lo mejor una pantomima que se podría volver a repetir una y otra vez.' Pasa igual con los poemas de Diego, cuya acción se escribe a veces como pantomima, o vuelve a repetirse, para parecer menos acción verdadera que simbólica.

\section{PANTOMIMA}

Viene la muerte, en figura de General de Brigada. El Escribiente la recibe con excesos.

Se sirven pasteles, granizados, almendras. La muerte participa de todo con gustosa gravedad. El Escribiente habla y habla.

Luego la muerte, en figura de General de Brigada, toma al Escribiente del brazo y lo conduce en silencio a la puerta (Versiones).

\footnotetext{
' Se ve otra forma de representación estilizada en los poemas de Diego en las barajas, dibujos planos y artificiales como los iconos. También esto puede ser una referencia a la corte de barajas que presenta Lewis Carrol en Alicia en el pais de maravillas, cuya filosofía lingüística expone Tweedledum: "Words mean whatever I want them to"
} 
Los gestos no aparecen naturáles sino simbólicos; las acciones no concluyen una vez hechas, sino que se pueden repetir una y otra vez, sin jamás ingresar al pasado. Siempre presentes, vuelven a repetir sus gestos.

La repetición sirve para subrayar el objeto y/o la aserción. El círculo así dibujado parece gesto ritual, o una penumbra alrededor de las cosas (semejante, quizás, a las penumbras que se ven detrás de las cabezas de personajes sagrados en los iconos).

\section{COMO LA NOCHE}

La piel del viejo, en ansiosos pliegues se ajusta a la semilla o hueso del rostro

La piel voraz del viejo se ajusta a la semilla o hueso del rostro, seco de sueños.

La semilla o hueso del rostro, el esplendor de cuya fealdad rebosa mi corazón como la noche (Versiones).

Las comillas sirven para distanciarnos más de los poemas, para advertirnos que son representaciones, tal como hace la cortina en frente de los iconos. La semilla o el hueso del rostro que se mueve cada vez más hacia el frente tiene varios significados posibles. Una comparación obvia es la noche, como indica el título, cuyo progreso es igualmente inexorable; también evoca la vejez o la muerte - lo físico aquí se confunde otra vez con lo abstracto. Mientras el rostro nos acerca, lo que hay detrás del rostro crece también, sugiriendo su función de cortina del más allá. Erigida esta imagen de la semilla o hueso del rostro, subrayada y descrita por fin con fealdad espléndida, deja de ser prosaica o puramente física y resuena en otra dimensión, sugiriendo sentidos que sobrepasan las palabras.

Igual como en consideraciones de representación icónica, la vista se destaca en la poesía de Diego como el sentido de mayor importancia. Emplea los demás sentidos infrecuentemente; los objetos se descubren a la vista y no al tacto u oído. Los antiguos cristianos estaban de acuerdo sobre esta cuestión también. Según Theodore de Studion, "sight precedes hearing both in the location of its organs and in the perception by the senses. For first one sees something and then transmits the sight to the sense of hearing" (Barasch 277). La vista, según ellos, es a la vez más inmediata y más cercana a Dios. En la poesía escueta de Diego, alcanza prioridad absoluta.

\section{EL ARROBO POSMODERNO}

Foucault comparte con Emerson algunas especulaciones sobre la génesis de la palabra. Medita en Les mots et les choses sobre la torre de Babel, de la correspondencia entre la palabra y la cosa antes de este acontecimiento mítico-histórico y de la brecha que aparece ahora entre los términos.

Sous sa fore première, quand il fut donné aux hommes par Dieu lui-même, le langage était un signe des choses absolument certain et transparent, parce qu'il leur ressemblait [...] Cette transparence fut détruite à Babel pour la punition des hommes (Foucault 51). 
Pero mientras Emerson piensa recuperar la unión de palabra y naturaleza (y así pasar a la dimensión espiritual), Foucault deja esa unión en el pasado cuasi-mítico, irrecuperable. Para él esta brecha es insuperable, y toda sabiduria padece de artificio.

Foucault advierte, ya lejos de Emerson, la opacidad del lenguaje; las representaciones no derivan su significado del mundo, sino que lo llegan a ofuscar; todo lenguaje y significado reside dentro de ellas. No se puede decir con certeza que Diego haya leído a Foucault, ni menos viceversa, pero podemos afirmar que compartían un zeitgeist. Cuando Foucault habla sobre el desmadejamiento del sistema signo-significado y el crecimiento del vacío entre los términos y las cosas, podemos considerar que Diego también consideraba estas posibilidades.

El esfuerzo que hace Diego por nombrar las cosas corresponde en parte a tal vacío, volviendo a las raíces del lenguaje para hacer aserciones de la manera más básica: "El viento es un hombre pequeñito" y "Las nubes son unos sabios inocentes". Desde esa aserción mínima, la articulación de la equivalencia, Diego abre el objetivo un poco para desarrollar la idea, y después vuelve a afirmar la equivalencia otra vez. Siempre se preocupa de la probabilidad de perderse en el lenguaje. Se nota que el verbo de mayor uso en los poemas de Diego es el verbo "ser". El lenguaje se reduce a su nivel más básico: un nombre, el verbo ser, un atributo. Según Foucault, todos los verbos tienen en la raíz el verbo ser.

Mais faire venir tout de suite en pleine lumière ce que le constitue : le verbe affirme [...] Il y a proposition -et discours-lorsqu'on affirme entre deux choses un lien d'attribution, lors-qu'on dit que ceci est cela. L'espèce entière du verbe se ramène al seul que signifie: être (109).

Igualmente, la derivación de todos los signos y categorías es el juntar de las cosas bajo nombres. "le mot désigne, c'est-à-dire qu'en sa nature il est nom" (112). Las frases más básicas, que buscan las raíces de la lengua, emplean el verbo ser y un nombre. Diego intenta restablecer, o recuperar, la verdad en el nivel más básico de la lengua - un proyecto consciente de su compromiso.

Para Foucault esta brecha es insuperable, pero el filósofo erige de la brecha misma otra transcendencia. Indica que el libro Les mots salió de una experiencia trascendental ocasionada por una lectura de Borges:

Ce livre a son lieu de naissance dans un texte de Borges. Dans le rire que secoue à sa lecture toutes les familiarités de la pensée - de la nôtre; de celle que a notre âge et notre géographie-, ébranlant toutes les surfaces ordonnées et tous les plans que assagissent pour nos le fousennement des êtres, faisant vaciller et inquiétant pour longtemps notre pratique millénaire du Même et de l'Autre (7).

Borges le había ofrecido una taxonomía china que lo volvió loco con su falta de sentido, mostrándole la naturaleza arbitraria de nuestras divisiones y taxonomías. Este arrobo, sin embargo, repite en otros términos las experiencias trascendentales de Emerson y los cristianos. De una manera muy rara, Foucault llega, por medio del reconocimiento de la brecha entre la palabra y su significado, a una comunicación profunda - con Borges, 
quizás con sus propios lectores- en el plano espiritual. Muestra también una semejanza sugerente con los misterios de ciertas sectas esotéricas, tanto dentro como fuera del cristianismo.

Ese arrobo, en el caso de Foucault, tiene sus raices filosóficas en Heidegger. Heidegger destacó, en Being and Time y su "Letter on Humanism", un "transcendens" que ofrecía el poder a cada cual de salir de viejos modos de pensamiento y re-encontrar el mundo de nuevo, ahora con la posibilidad de transformarlo. Esto se lograba al contemplar lo "no-pensado": la nada, o la muerte. James Miller, en The Passion of Michel Foucault, ha investigado esta transcendencia bien, en un pasaje que parece una buena descripción del proyecto de Diego:

To surrender one's customary inhibitions and descend into what Heidegger called the 'unthought,' the thinker had first to 'learn to exist in the nameless.' To accomplish this paradoxical task, it was not philosophy but poetry and art that might light the way. 'Language,' as Heidegger famously asserts, 'is the house of Being.' Probing beyond the limits of reason, thinking sooner or later finds itself without statute or rule, structure or order, and face to face with nothing.[...] Emerging from his 'adventure' into 'the unthought,' the thinker would find the world, as before, untouched and unaltered, but with its aura of primordial mystery (and possible horror) restored (50-51).

Heidegger afirma que, para evocar ese transporte, para revelar con palabras lo que no se puede decir, el filósofo tiene que escribir como un poeta. Borges cumple bien con este prognóstico, dejándonos un patrón de cómo comunicar el arrobo posmoderno: él llama la atención a la brecha empleando palabras en un orden que subvierte nuestras categorías, dejando resaltar su arbitrariedad.

Diego también sigue este modelo; al enfocar el misterio de la muerte, señala la imposibilidad de nuestro pensamiento ante un vacío tan grande; en sus afirmaciones, su repetición de los nombres de las cosas, señala la arbitrariedad de los nombres. En "Entre las aguas" (Versiones) vemos la inquietud de que los hombres no puedan saber el verdadero nombre de la lluvia (ya visto en "Viene" como símbolo de la naturaleza sagrada). Aparece una brecha entre "la lluvia" y la lluvia; sólo las ranas (criaturas antiguas, símbolos del subconsciente, previo(s) al lenguaje en la historia y la figuración) saben el verdadero nombre y se ríen de nosotros (con la misma risa ontológica del arrobo posmoderno).

\section{ENTRE LAS AGUAS}

Las ranas cantan entre la lluvia, a la otra parte de las aguas.

Las ranas viven al extremo del jardin, en las fronteras de los pueblos o allá donde la voz llega como terciopelo.

La lluvia es sombría como un bosque, y en lo más hondo del bosque las ranas cantan.

La lluvia es vasta como un país, y viven en las provincias del interior distante.

Vigorosas y alegres, saben que la lluvia no es triste. 
Ríen suavemente, al decir solemnes el secreto, gozoso nombre de la lluvia, pero en adivinanza.

Ríen para sí, escondidas, impenetrables.

Las ranas esconden el verdadero nombre de la lluvia, para ellos un nombre secreto, gozoso, tal vez sagrado, como el verdadero nombre de Dios un nombre que, no corrompido por la vocalización, sirve de clave trascendental. A diferencia del sistema emersoniano, el plano espiritual, aquí se alcanza no por pronunciar las palabras más naturales, sino por indicar la misma imposibilidad de tal referencia.

El poema "Las ranas" (Alfabeto del Mundo) de Eugenio Montejo, destaca más estas conexiones: en un poema similar al de Diego, hace referencia a Platón ${ }^{2}$ y al taoísmo. El poema termina:

Por hoy me bastan las voces de las ranas, quiero oírlas croar esta noche más cerca dejando que me llenen los sentidos con su taoísmo solitario hasta que se borren los enigmas del mundo.

En sus coros me entrego a la máxima gracia.

Los lectores de Diego, sin embargo no consiguen salir de la incertidumbre tan fácilmente. El sentido de la risa de las ranas de Diego no se ofrece abiertamente como el croar de las ranas de Montejo (cuyo "alfabeto [tiene] una sola vocal"). Las ranas de Diego no nos permiten, como las ranas de Montejo, llegar "a la máxima gracia". Las ranas de Diego, al fin de cuentas, no hablan un lenguaje que podemos comprender; mantienen sus secretos fuera de nuestro alcance. Quizás por este mismo hecho no han perdido "el secreto, gozoso nombre de la lluvia". No borran "los enigmas del mundo"; guardan su verdad como adivinanza y nos dejan en la suspensión de la ambigüedad ontológica con su risa impenetrable. Quizás ríen por esto mismo: la misma suspensión o asombro es en sí la transcendencia que buscamos.

\section{El NO SABER}

El no saber está bien representado en la poesía de Diego por la Muerte. ${ }^{3}$ Esta persona oscura, sin forma, persigue al lector como su propia sombra, riéndose a sus espaldas, pero aquietándose cuando se vuelve para ver quién ríe. La muerte representa no solamente un tiempo después del tiempo de la vida, sino también la región que queda constantemente fuera de nuestra comprensión. La muerte no se representa directamente sino que siempre se

\footnotetext{
${ }^{2}$ Dice Montejo en el poema, "Tal vez sea un ángel esa sombra/ que se eleva a la puerta de mi caverna./ No me consta./ La oscuridad de Dios nunca deja ver nada claro". El ángel es una de las sombras (en la primera etapa del relato, cosas artificiales) que los prisioneros de la caverna de Platón confunden con las verdaderas cosas. Montejo cuestiona a Dios por ponernos en la oscuridad, y busca otra salida en el canto de las ranas.

${ }^{3}$ Un hecho consistente con la tradición posmoderna de Foucault ( $\mathrm{y}$ antes Heidegger).
} 
equipara con algo - en el poema "Pantomima", aparece vestida de General. No se puede percibir la muerte en sí; se necesita entenderla contemplado otras cosas más palpables. En el poema, "Versiones", que procede de una serie de equivalencias, se destaca bien este proceso:

\section{VERSIONES}

La muerte es esa pequeña jarra, con flores pintadas a mano, que hay en todas la casas y que uno jamás se detiene a ver.

La muerte es ese pequeño animal que ha cruzado en el patio, y del que nos consuela la ilusión, sentida como un soplo, de que es sólo el gato de la casa, el gato de costumbre, el gato que ha cruzado, $y$ al que ya no volveremos a ver.

La muerte es ese amigo que aparece en las fotografias de la familia, discretamente a un lado, y al que nadie acertó nunca a reconocer.

La muerte, en fin, es esa mancha en el muro que una tarde hemos mirado, sin saberlo, con un poco de terror (Versiones).

"La muerte es ..." una jarra, un pequeño animal, ese amigo, esa mancha, todas cosas que se pueden percibir, que tal vez los lectores hayamos visto; y por eso podemos entender, pero que siempre, con su misterio ambiguo, apuntan hacia el más allá (de la vida, del lenguaje, de la comprensión): la muerte. La equivalencia funciona de muchas maneras: las cosas, antes cotidianas, se desprenden de su descanso en el mundo conocido al compararlas con la muerte. La experiencia de su contemplación se mezcla, entonces, con el presentimiento de la muerte, agregándoles una nueva profundidad. Y al contrario, la muerte se naturaliza al verla dentro del ámbito familiar.

El poema no solamente evoca emociones profundas, sino que turba el acto más básico de la comunicación, la equivalencia. La muerte es estas cosas; viceversa, ellas son la muerte. Aceptar estos planteamientos desnaturaliza el mismo verbo ser. Enmaraña mientras afirma y juega alrededor de las equivalencias propuestas, plantando las semillas de su transcendencia múltiple, incierta - no precisamente la unión mística con el mundo tangible que propone Emerson, ni el conocimiento del espíritu divino que destacan los ortodoxos, ni el paroxismo lingüístico de Foucault, sino un poco de todos, y una incertidumbre grande.

\section{UBICACIÓN SOCIAL DE LO PROFUNDO}

El conocimiento de la multiplicidad de la trascendencia permite a Diego elegir conscientemente los términos de su espiritualismo. De acuerdo con su materialismo, Diego nombra las cosas de su entorno, cosas cubanas, hechas por manos cubanas, vistas en calles y casas cubanas; todas las posibilidades del espíritu se ubican en las cosas humildes de su país. Dentro del país el enfoque es igualmente preciso; en Cuba, especialmente la de antes de la Revolución, no todas las cosas son cubanas; habrá que recordar los efectos sociales de la dependencia económica. Su búsqueda de lo ordinario (y su transcendentalismo) se centra 
precisamente en lo auténticamente cubano; por medio de este enfoque, crea también un mundo, y una nación, simplificados y purificados.

Mientras otros escritores del período consideraban más la influencia social del colonialismo económico estadounidense y la situación política del país (podemos pensar en Alejo Carpentier, Cabrera Infante o Nicolás Guillén), Diego rehusó tratar directamente de estos temas en su obra. Como Voltaire, "cuidaba su propio jardín". Sin embargo, este jardín poético, sembrado sólo con lo cubano, ejercita una influencia política a su manera: el elogio de lo cotidiano y lo nacional fortalece y apoya una perspectiva nacionalista.

Aunque para Diego la idea de "arte comprometido" tiene tanto sentido como "carpintería comprometida o una albañilería comprometida" (Bejel 46), el contacto profundo con la experiencia humana que él propone como base de la poesía naturalmente tocará la política. Como miembro del grupo Orígenes, Diego compartía una "necesidad de poner pie en lo real, en las realidades del país, que en aquellos años se iba desintegrando poco a poco" (44). Su primer libro, entonces, En la calzada de Jesús del Monte, se dedica a una calle de su querida Habana. Mientras nunca hizo de la política el tema central de su poesía, afirmó la responsibilidad social del artista, de contribuir con su obra a la sociedad; la estética no se separa de la ética. Sin esta conexión, la comunicación verdadera sería imposible.

Diego desecha una fuente omnipresente del lenguaje moderno: más que la literatura, o las cosas mismas, o hasta la conversación, las fuentes modernas del lenguaje son los mass media - un tema importante para otros escritores de su tiempo. La omisión de esta fuente lingüística y ontológica de su poesía representa un rechazo determinado de la sociedad capitalista y de su realidad sígnica. Al considerar los cambios efectuados en el mundo por la introducción de los nuevos medios de comunicación, Diego llega a conclusiones similares a las de los situacionalistas franceses: que la vida propia y la vida presentada en los mass media no son ni iguales ni semejantes. Como dice él, "El mundo de la T.V. y los anuncios puede muy bien convertirse en algo como un limbo infernal" (Poetas Comunicantes 162). $\mathrm{Al}$ volver su cara hacia la materia y la vida experimentada directamente, Diego arraiga las palabras y la espiritualidad en lo cotidiano, lo auténtico, evitando el estrato alienado de los medios modernos de comunicación, con su realidad lingüística peligrosamente absorbente.

Mientras evita el infierno de la alienación capitalista, Diego tampoco erige un cielo fuera del mundo cotidiano. Los poemas que ofrecen un sentido religioso siempre lo asientan precisamente en el mundo físico y humilde del hombre común. En el siguiente poema, por ejemplo, se compara la noche con el abrigo de un pobre:

\section{LA NOCHE}

La noche es el abrigo de un pobre, que cuelga, desgarrado y espeso, en un rincón oscuro.

A través de sus rotos se filtra el resplandor magnífico del fogón, y lo conmueven las ráfagas de la fiesta lejana y la voz profunda del sirviente que dio al pobre de comer.

Llega un momento en que recogerá despacio su abrigo, cuando descienda, entre los emplomados vidrios, la luz al polvillo de oro en el rincón (Versiones). 
Lo de más allá, el "resplandor magnífico", acepta varias interpretaciones: el sol, el fogón, Dios o el cielo cristiano, cualquier experiencia trascendental. No es difícil imaginar que el pobre puede ser Cristo; así que el abrigo roto funciona como la barrera de los iconos (o, quizás, la noche), que antes escondía el cuerpo del pobre y ahora esconde el fogón (¿el sol o Dios?). Esperamos, además, el misterioso "momento en que recogerá despacio su abrigo" - el apocalipsis, la iluminación, la muerte, el día. Los vidrios recuerdan el poema "Viene", donde indicaban una distancia y prometían una resurrección lingüística; en el momento en que venga la luz, esta barrera desaparecerá y se encenderá el "polvillo de oro en el rincón", quizás el alma humana.

Sin embargo, este sentido profundo no emerge sin la existencia de otras posibilidades y tampoco escapa del mundo cotidiano. El mismo abrigo viejo se podría encontrar en cualquier casa; después de todo, la luz desciende después de la noche todos los días y abrigos iguales son recogidos por sus dueños al salir. El "polvillo de oro" podría ser esto mismo, una recompensa por la benevolencia del sirviente. En tres estancias breves el poema sugiere una epifanía, vuela a las alturas del misterio y vuelve a la tierra. El lector termina el poema y, como el pobre, se va, pero la epifanía - el misterioso, reluciente polvillo de oro, se ha descubierto en el rincón de un poema cubano.

\section{Obras Consultadas}

Barasch, Mosche. Icon. New York: New York University, 1992.

Bejel, Emilio. "La poesía de Eliseo Diego". INTI: Revista de literatura Hispánica 18-19 (Fall-Spring 1984).

Benedetti, Mario. Los poetas comunicantes. Montevideo: Biblioteca de Marcha, 1972. Carrol, Lewis. Alicia en el país de maravillas.

Diego, Eliseo. Versiones. La Habana: Unidad Productora 08, 1970.

Muestrario del mundo o Libro de las maravillas de Boloña. Madrid: Visor, 1978.

Emerson, Ralph Waldo. "Nature". Norton Anthology of American Literature, 1989.

Eyzaguirre, Luis. "Eugenio Montejo: Poeta de fin de siglo". INTI: Revista de literatura Hispánica 37-38 (Spring-Fall 1993).

Fleites, Alex. "Fragmentos de una nueva conversación en la penumbra". Gaceta de Cuba (julio 1990).

Foucault, Michel. Les mots et les chose. París: Gallimard, 1966.

Gates, Henry Louis. The Signifying Monkey. New York: Oxford University Press, 1988.

Heidegger, Martin. Being and Time. John Macquarrie y Edward Robinson, trads. New York: Harper \& Row, 1962.

"Letter on Humanism". Basic Writings. New York, 1977.

Hernández Novás, Raúl. "Nombrar las cosas". Nuevos críticos cubanos. Ciudad de La Habana: Editorial Letras Cubanas, 1983.

Irwin, John. American Hieroglyphs. Yale, 1980.

Matas, Julio. "El espacio ideal de la memoria: La poesía de Eliseo Diego". Inprevue 1 (1988).

Miller, James. The Passion of Michel Foucault. Anchor/Doubleday, 1994. 
Montejo, Eugenio. Alfabeto del mundo. México: Tierra Firme, 1988.

Padura, L. "Eliseo Diego: Descartes e inéditos". Gaceta de Cuba (July, 1990).

Paine, Thomas. The Age of Reason. New York: Thomas Paine Foundation, 1960.

Quintero, Aramis. "Las extrañas lindes". Gaceta de Cuba (July, 1990).

Rouse, J.G.C. (ed.) Great Dialogues of Plato. New York: Signet, 1956.

Sahas, Daniel. Icon and Logos. Toronto; Buffalo: University of Toronto Press, 1986.

Sainz, Enrique. "Eliseo Diego: Definición de un poeta". Revista Iberoamericana LVI/152153 (julio-diciembre, 1990): 1203-1210.

"Sitios, cosas, memorias". Gaceta de Cuba (July, 1990).

Whitman, Walt. Leaves of Grass. New York: Signet, 1980. 